\title{
The teaching of medical ethics: University College, Cork, Ireland
}

\author{
Dolores Dooley Clarke Department of Philosophy, University College, Cork
}

\begin{abstract}
Dolores Dooley Clarke describes how the course in medical ethics at University College, Cork is structured, how it has changed and how it is likely to change as time goes on. Originally, the students seemed to view it as an intrusion 'to be tolerated' in their programme of 'strictly medical' studies. However, having moved on from that and away from the lecturer always being a Roman Catholic priest as well as a member of the Philosophy Department, the students now appear to view it as producing a stimulus for a new interest in the area of ethics for physicians. This seems to have come about through the more extensive participation of students in researching and presenting issues of medical ethics.
\end{abstract}

The medical course of studies at University College, Cork, extends over a period of not less than five academic years from the date of registration as a medical student. Medical ethics is a required course to be taken in the third year of studies, and the course consists of two class meetings a week for the duration of the academic year. Several historical features of the course in medical ethics at UCC are relevant to a description of the course as it has evolved over the last two years.

Medical ethics has traditionally been viewed by students as something of an intrusion to be tolerated in the overall rigorous programme of 'strictly medical' studies, that is, those courses which directly contribute to the development of medical expertise in healing and sustaining physical life. So far medical ethics has not been methodically or otherwise consciously integrated into the overall medical curriculum but integration is a desirable objective for the very near future. Students have traditionally wondered how medical ethics is supposed to complement, supplement, or in any way contribute to, their training as medical professionals. A teacher of medical ethics at UCC does well to recognise that students are generally sceptical of the necessity of a required course in ethics.

Two other features of the course have further reinforced the impression that medical ethics is not relevant to the training of physicians. The lecturer has not been a member of the Medical Faculty but traditionally, he has been a Roman Catholic priest, and this fact has, however unintentionally, raised questions about the extent to which the course in medical ethics was a reiteration of Catholic moral teaching on such issues as con- ळ traception, abortion, sterilisation, euthanasia. Students operated on the implicit assumption that:whatever issues were discussed in the course must $\vec{\omega}$ somehow, in the final analysis, be rendered com-or patible with the authoritative moral teachings of the Catholic Church. On this assumption, the scope for open and critical reflection on issues of medical ethics was often effectively curtailed. Nowo medical ethics is taught by a lecturer in the Phil-o osophy Department who is not a cleric but someonewho is familiar with the Roman Catholic traditions which has, most pervasively, influenced the moral $\frac{0}{3}$ formation of medical students at UCC.

The course can be described by looking at four $\overrightarrow{0}$ main objectives of the present teaching approach : I) Use of the inductive method in which studentsi present specified topics in medical ethics

2) An examination of recurring attempts to blur the distinction between medical expertise and ethicalo decision making

3) An analysis of medical-ethical problems with the aim of distinguishing medical facts, legal ramifica-oํำ tions, and value presuppositions which operate in attempts to resolve the ethical issues, however tentative the resolution may be

4) Attempts to make explicit the relationship between morality and religion.

Student presentations and the inductiveo approach

To give an overall picture of the area of medica ethics, and, preceding the students' presentations a series of lectures is given. These provide a brief survey of the historical development of medicalos ethics beginning with the Hippocratic school andr concluding with discussions of the many factorsn which have contributed to an expanded statement $t^{\omega}$ of the scope and significance of medical ethics for the practising physician today. These introductory? lectures deliberately omit any reference to thes questions of defining ethics, choosing among com peting ethical frameworks and the importanto question of justification for ethical claims. The purpose of the omission is to allow these questions to surface in the context of student discussions on
specific issues.

Students choose topics for discussion from aी list provided by the lecturer, and are responsible 
for researching available material and presenting the problem to the class. Six students prepare the issue, four of them presenting the multiple facets of the topic and two a critical commentary on various ethical positions which emerge from the literature and appear central to the discussion. Questions, criticisms and clarifications are invited from the rest of the class after the presentation is completed. The presentations are intended to inform the class of the nature and complexity of the problems and elicit questions on ethical positions which may have been assumed by individual members of the student panel.

The topics provided for students vary, depending on the interests of each group and the extent of the current debate surrounding the issues. A sample list includes the following: Haemodialysis and the allocation of scarce medical resources; the Karen Quinlan case; attempts to specify more adequate criteria for the determination of death, abortion, sterilisation, contraception, euthanasia, homosexuality, experimentation on human subjects and the related problem of consent, dilemmas in the treatment of spina bifida and care of the dying.

Students are encouraged to use any and all resources available for an adequate and comprehensive review of their chosen topic. The library is only a starting point and the more adventurous, students show their resourcefulness by asking the help of general practitioners, medical specialists and related health professionals who have expertise and direct acquaintance with the topic under study. The students are also encouraged to invite those who are interested and willing to provide information to speak to the class and take part in the discussions. The students taking the medical ethics course are actively involved in their own clinical work during the third medical course and this often provides a basis from their own experience to illustrate the issues discussed.

Presentations by students inductively lead to the formulation of general philosophical problems which are seen to recur. Examples of such problems include: What are the requirements of informed consent in the doctor-patient relationship? What clarification and justification can be offered for patients' claims to possess certain rights in the context of medical treatment? What criteria can be offered in justification for a physician making judgments concerning the quality of life of a patient which result in a decision to withhold medical treatment from certain patients? Is it possible and desirable to specify certain criteria which must be satisfied if a given entity, for example, a fetus, is it to be treated as a 'human being' ? Can any limits be specified to the physician's primary obligation to sustain life?

Where such questions are not made explicit by the students, the lecturer assumes the role of doing so. Attempts to clarify and refine these questions continue throughout the course and more sustained discussion of them follows when all the presentations have been completed. The method of allowing the complex ethical questions to emerge in the context of concrete issues has the effect of showing them not to be of merely academic philosophical concern.

\section{Distinction between medical expertise and ethical decision making}

In the presentation and discussion of the issues, students often tend to blur the sometimes rather fine distinction between a question of medical expertise and one concerning ethical judgment. Considerable attention is given to the specifically medical facts of each issue, and the indications and contra-indications for recommended medical treatment are noted. Problems of diagnosis and prognosis which are clearly disputable in current medical research are also cited as relevant to an adequate coverage of the problem. In assessing any problem of medical ethics, the line of demarcation between a straightforward medical decision and an ethical judgment is not always obvious. Indeed, to talk of demarcation is somewhat misleading since it suggests that there is a specific and discernible point in the continuum of decision making where medical expertise stops and ethical judgments begin. To suggest this would be tantamount to proposing a simplistic model of ethical decision making in medical contexts. Medical facts of any case clearly provide supportive reasons for the decisions taken but those decisions may not be justified by medical facts alone. Whether or not to withhold specified medical treatment (including antibiotics) from certain spina bifida patients may appear obvious and advisable in terms of a medical team's prognosis. However, what is often left implicit is a judgment that the quality of life of the patient is not worth living and therefore should not be prolonged by continued treatment. The case study of Karen Quinlan provides yet another illustration of the inadequacy of medical expertise alone to make the necessary decisions of giving or withholding treatment. The objective aimed at is to try and clarify the interdependence and at the same time distinguish between the medical assessment and ethical judgments. The latter, it is argued, require analysis and justification not forthcoming from medical expertise taken in isolation.

\section{Medical facts, legal ramifications and value presuppositions}

Part of the student's task in presenting medical- $\stackrel{\mathbb{Q}}{\square}$ ethical issues is to try and make explicit the many facets of the particular problem. These facets 8 include at least attention to distinguishing the relevant medical facts of cases cited as well as 
value presuppositions that may be operative in making ethical judgments. It is argued that only in trying to make value presuppositions explicit, can they be scrutinized to see whether they are instances of unexamined prejudices or otherwise unwarranted assumptions. In addition, medical students often admit to being unaware of the legal ramifications of many decisions which might have to be considered in response to patients' requests. In the fourth year of the medical programme, a course in medical jurisprudence is required and in that course the medico-legal questions involved in questions of legitimacy, infanticide, certification of lunacy, determination of death, are discussed. However, certain issues which are presented in medical ethics raise complex questions about the relationship between law and morality. For example, in the Republic of Ireland the anomaly exists in the law whereby it is legal to import contraceptives but illegal to sell them. The desirability of legalising the sale of contraceptives remains today as one of the controversial issues which directly affects the medical practitioner. A question for discussion in class is the extent to which health professionals should be more politically active in trying to effect changes in legislation to make certain contraceptives available without prescription. Considerable attention is also given to the fact that at present abortion is illegal in the Republic. Recent figures published show that hundreds of women from Ireland annually go to England to procure abortions legalised under the I967 legislation. The political and cultural climate in the Republic is currently not disposed to introduce legislation to permit abortions for anything less than the most overt and serious of therapeutic reasons. Thus, while the law forbids abortion on demand, medical students are aware that they may be in the position of counselling women who may be seeking referral for an abortion. In considering the moral dilemmas involved in abortion, the question of the status of the fetus inevitably becomes a central issue. While it is clear than an individual's convictions on the 'human' character of the fetus may well determine his or her moral stand on abortion, it is not equally obvious that the determination of the 'human' character of fetal life is not a matter of medical fact. As Bok has put it:

'The different views as to when humanity begins are not dependent upon factual information alone. Rather, these views are representative of different world views, often of a religious nature, involving deeply held commitments with moral consequences. There is no disagreement as to what we now know about life and its development before and after conception; differences arise only about the names and moral consequences we attach to the changes in this development and the distinctions we consider important.'
Punitive legislation for male homosexuals like wise still exists in Ireland and this state of affairs notably provokes much debate over the dilemm of the physician confronted with a patient who. openly states a preferred homosexual orientation $\vec{p}$ While it is true that the legislation prohibiting male homosexuality is not regularly enforced, the current status of the law would seem to commip psychiatrists, therapists or psychologists to counse $\vec{\Phi}$ the patient in the direction of legal heterosexualityou Tensions remain between existing laws which prohibit certain practices and the moral decisions of individuals (patient or physician) to condone such practices. The entire area of the relationship betweein law and morality deserves more sustained attention and public involvement than the Republic of Ireland has yet witnessed. The changes which might be advisable or desirable are not at alfo obvious but public debate may well provide the forum for beginning such an assessment. Medica $\bar{P}$ students are encouraged to enter into this debate since they are most likely to be caught in the conflict of contradictions between what is legallo allowed and what is judged morally defensible. The relationship between morality and religion Many complex factors contribute to the shaping of moral reflection, moral concepts and moral judg ments about what should be encouraged as con $\frac{0}{0}$ ducive to specified ends of man. The Republic of Ireland has a population which, at least nominally $\overrightarrow{\vec{D}}$ is over 90 per cent Roman Catholic. Consequently most of the medical students at UCC come to medical ethics with a firm foundation in a relatively. homogeneous religious tradition. While the tradition and moral teachings of the Roman Catholic Church are not taken lightly by the students, many of them are receptive to a re-examination of their mora presuppositions which have derived from this religious tradition. It would be myopic for any lecturer in medical ethics at UCC to exclude the strong influence exerted by the religion of the majority of Irish people in the Republic, as it would be unrealistic to proceed with questions of medical ethics as if students could approach them with a religious tabula rasa. The course is structured neither as an unreflective reiteration of any specific ${ }^{\omega}$ set of religious teachings nor as a studied refutation of them. Students are encouraged to examine the issues with reference to many, diverse and often contradictory positions on the moral implications of certain practices which confront them as physicians. Appeals to authority as a form of justification for positions taken are considered starting points for ethical analysis rather than warranted conclusions. $\varrho$

\section{Proposals for change}

The extensive participation of students in research 
and presentation of issues of medical ethics has provided the stimulus for effecting a new interest in the area of ethics for physicians. While this basic format will continue, changes are envisaged along the lines of involving more of the medical staff as people who will not only provide relevant lecture material but also be present for discussions in seminars of problems directly related to their areas of expertise. The person mainly responsible for structuring the course will, in the foreseeable future, be a lecturer from the philosophy department, and his main tasks are to keep informed of the current issues in medical ethics, to continue his or her self education in medical matters as much as is feasible and try to restructure the course to include a more broadly based interdisciplinary approach.

It is also envisaged that the members of the Medical Society of UCC will also be able to contribute some of their time and energy to organising discussions on issues in medical ethics which most directly affect the physician practising in Ireland. This would be an extracurricular venture that could profitably assist in keeping the area of medical ethics a going concern throughout the five-year medical curriculum.

\section{References}

${ }^{1}$ Bok, Sissela (1974). Hastings Center Studies, II, No. I, 33-52. Institute of Society, Ethics and the Life Sciences.

*Brody, Howard (1976). Ethical Decisions in Medicine. Little, Brown and Company, Boston, Massachusetts.

*Hepburn, R. W. (1976). Morality and religion. fournal of Medical Ethics, 2, 93-94.

*The references to Brody and Hepburn were not directly referred to in the text. I enclose them as useful references for the reader to pursue. 